\title{
Induction of autophagy mitigates TDP-43 pathology and translational repression of neurofilament mRNAs in mouse models of ALS/FTD
}

Sunny Kumar, Daniel Phaneuf, Pierre Cordeau Jr., Hejer Boutej, Jasna Kriz and Jean-Pierre Julien (D)

\begin{abstract}
Background: TDP-43 proteinopathy is a pathological hallmark of many neurodegenerative diseases including amyotrophic lateral sclerosis (ALS) and frontotemporal dementia (FTD). So far, there is no therapy available for these neurodegenerative diseases. In addition, the impact of TDP-43 proteinopathy on neuronal translational profile also remains unknown.

Methods: Biochemical, immunohistology and assay-based studies were done with cell cultures and transgenic mice models. We also used Ribotag with microarray and proteomic analysis to determine the neuronal translational profile in the mice model of ALS/FTD.

Results: Here, we report that oral administration of a novel analog (IMS-088) of withaferin-A, an antagonist of nuclear factor kappa-B (NF-kB) essential modulator (NEMO), induced autophagy and reduced TDP-43 proteinopathy in the brain and spinal cord of transgenic mice expressing human TDP-43 mutants, models of ALS/FTD. Treatment with IMS-088 ameliorated cognitive impairment, reduced gliosis in the brain of ALS/FTD mouse models. With the Ribotrap method, we investigated the impact of TDP-43 proteinopathy and IMS-088 treatment on the translation profile of neurons of one-year old hTDP-43 ${ }^{\text {A315T }}$ mice. TDP-43 proteinopathy caused translational dysregulation of specific mRNAs including translational suppression of neurofilament mRNAs resulting in 3 to 4-fold decrease in levels type IV neurofilament proteins. Oral administration of IMS-088 rescued the translational defects associated with TDP-43 proteinopathy and restored the synthesis of neurofilament proteins, which are essential for axon integrity and synaptic function.

Conclusions: Our study revealed that induction of autophagy reduces TDP-43 pathology and ameliorates the translational defect seen in mice models of ALS/FTD. Based on these results, we suggest IMS-088 and perhaps other inducers of autophagy should be considered as potential therapeutics for neurodegenerative disorders with TDP-43 proteinopathies.
\end{abstract}

\footnotetext{
* Correspondence: jean-pierre.julien@fmed.ulaval.ca

Department of Psychiatry and Neuroscience, CERVO Brain Research Centre, University Laval, 2601, Chemin de la Canardière, Quebec City, QC G1J 2G3, Canada
}

C C The Author(s). 2021 Open Access This article is licensed under a Creative Commons Attribution 4.0 International License, which permits use, sharing, adaptation, distribution and reproduction in any medium or format, as long as you give appropriate credit to the original author(s) and the source, provide a link to the Creative Commons licence, and indicate if changes were made. The images or other third party material in this article are included in the article's Creative Commons licence, unless indicated otherwise in a credit line to the material. If material is not included in the article's Creative Commons licence and your intended use is not permitted by statutory regulation or exceeds the permitted use, you will need to obtain permission directly from the copyright holder. To view a copy of this licence, visit http://creativecommons.org/licenses/by/4.0/ The Creative Commons Public Domain Dedication waiver (http://creativecommons.org/publicdomain/zero/1.0/) applies to the data made available in this article, unless otherwise stated in a credit line to the data. 


\section{Background}

Cytoplasmic mislocalization and aggregation of TDP-43 are a pathological hallmark of many neurodegenerative diseases including ALS, FTD, limbic-predominant agerelated TDP-43 encephalopathy (LATE) and Alzheimer's disease [1-7]. TDP-43 is a DNA/RNA binding protein predominantly localized in the nucleus and it helps in RNA transcription, splicing, trafficking and chromatin condensation [1, 2]. In addition, TDP-43 also participates in translational regulation [8-10]. TDP-43 cytoplasmic increase has been shown to suppress global translation by binding with RACK1 on polyribosome [11]. However, the impact of TDP-43 proteinopathy on neuronal translational profile in vivo remains unknown. Transgenic mice expressing TDP-43 mutations have been described by different groups and many of them exhibit pathological changes reminiscent of human ALS and FTD [12, 13]. Different studies showed that clearance of excess cytoplasmic TDP-43 ameliorated the disease pathology in such mouse models of ALS [3, 14, 15]. Previously, our group reported that in context of ALS cases, TDP-43 can interact with the p65 NF- $\mathrm{kB}$ subunit to enhance its signalling activity in the central nervous system (CNS) [16]. Recently, we reported that AAVmediated delivery of a single-chain antibody capable to block TDP-43 interaction with p65 NF-kB led to reduction of NF- $\mathrm{kB}$ activity and of TDP-43 aggregates in mouse models of ALS/FTD [3]. Reducing the NF- $k B$ activity ameliorated motor function in mouse models of ALS $[16,17]$. An extract of the medicinal plant Withania somnifera and its active compound Withaferin$\mathrm{A}$, an inhibitor of NF-kB signalling, conferred beneficial effects when administered in ALS/FTD mouse models $[14,16]$. A recent study has also shown that withaferin-A protects the dopaminergic neurons and motor function in aging rats [18]. Withaferin-A was found to disrupt the NF-kB essential modulator (NEMO) reorganization into ubiquitin-based signaling structures by covalently modifying Cysteine-397, producing a lack of IKK $\beta$ activation [19].

In the present study, we have derived and tested the efficacy of oral administration of novel semi-synthetic analog of withaferin-A named IMS-088, in transgenic mice models of FTD/ALS expressing human TDP-43 mutants. IMS-088 reduces NF- $\mathrm{kB}$ signaling activity but is less toxic than withaferin-A. Treatment of mice expressing hTDP-43 mutants with IMS-088 ameliorated cognitive deficits, reduced cytoplasmic TDP-43 aggregates and enhanced levels of autophagy markers. We also studied by mass spectrometry of newly synthesized peptides of ribosomes the impact of IMS-088 treatment on neuronal translational profile with the use of double transgenic RiboTag;hTDP-43 ${ }^{\mathrm{A} 315 \mathrm{~T}}$ mice. We report for the first time that TDP-43 proteinopathy causes a translational dysregulation of selective mRNAs, including substantial repression of neurofilament mRNAs. IMS-088 treatment mitigated TDP-43 pathology and it restored neurofilament protein synthesis in ALS/FTD mice.

\section{Methods \\ Cell culture}

Mouse microglial (BV2) and motor neuron like (NSC34) cells were stably transfected with pGL4.32[luc2P/

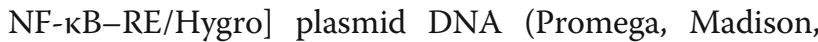
WI, USA). The vector expressed 5 copies of NF-kB response element that drives transcription of the luciferase reporter gene luc2P. These cells were cultured in Dulbecco's Modified Eagle Medium 16 (DMEM) supplemented with $10 \%$ fetal bovine serum. For clonal selection of the transfected plasmid these cells were cultured in $100 \mu \mathrm{g} / \mathrm{ml}$ hygromycin. HEK 293 cells were also used and was cultured in Dulbecco's Modified Eagle Medium (DMEM) containing 10\% fetal bovine serum. The culture media for all the cells, we added 100 units/ $\mathrm{ml}$ penicillin-streptomycin.

\section{Evaluation of luciferase activity assay}

To measure p65 luciferase activity, BV2 or NSC-34 cells $\left(5 \times 10^{4}\right.$ per well $)$ were seeded in 24 -well plates. The BV2 or NSC-34 cells were stimulated with $500 \mathrm{ng} / \mathrm{ml}$ bacterial lipopolysaccharide (LPS) or $40 \mathrm{ng} / \mathrm{ml}$ of TNF $\alpha$ respectively. In BV2 cell experiment, after $2 \mathrm{~h}$, the media was removed and new media containing LPS with or without IMS-088 or withaferin-A was added for next 2 h. Similarly, for NSC-34 cells after $4 \mathrm{~h}$ of TNF $\alpha$ incubation, media was replaced with media containing TNF $\alpha$ with IMS-088 or withaferin-A for $2 \mathrm{~h}$. Post-treatment, the media was removed, and cells were gently washed with $1 \times$ PBS, and then lysed using Glo Lysis buffer (Promega, Madison). Luciferase activity was measured using the Bright-Glo Luciferase assay system (Promega,Madison), according to the manufacturer's instructions. DMSO treated cells under similar conditions served as control. Results were expressed as mean of luciferase ac-

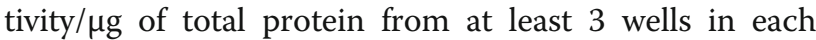
treatment condition for BV2 cells and 4 wells of each treatment for NSC-34 cells.

\section{Evaluation of cell survival}

BV2 and NSC-34 cells were seeded onto 24-well plates at a density of $5 \times 10^{4}$ cells/well. The treatment paradigm was similar as explained for luciferase assay. Post incubation with the drug, cell viability was measured using MTS assay using [3-(4,5- dimethylthiazol-2-yl)-5-(3carboxymethoxyphenyl)-2-(4-sulfophenyl)-2H-tetrazolium], as per the manufacturer's instructions (Promega, Madison). The absorbance of the formazan adduct formed 
was determined at $490 \mathrm{~nm}$ using an EnSpire 2300 Multilabel reader (Perkin Elmer, Waltham, MA, USA). Values were expressed as arithmetic measurement unit.

\section{Inhibition of Autophagosome/lysosome pathway}

Bafilomycin A1 (Sigma-Aldrich, USA), an inhibitor of Autophagosome/Lysosome pathway was used to test the effects of autophagy inhibition on IMS-088-mediated reduction of TDP-43 aggregation. HEK 293 cells were treated for $3 \mathrm{~h}$ with $50 \mu \mathrm{M}$ Ethacrynic acid (in serum free media). Then, Bafilomycin A1 (300 nM) with or without IMS-088 $(1 \mu \mathrm{M})$ was added to media for $6 \mathrm{~h}$. After treatment, analysis of insoluble, or soluble hTDP-43 was done with $6 \mathrm{M}$ urea and RIPA buffers respectively followed by immunoblotting.

\section{Sample preparation and immunocytochemistry}

HEK-293 cells were treated with $50 \mu \mathrm{M}$ of Ethacrynic acid (Millipore sigma) overnight with or without $1 \mu \mathrm{M}$ IMS-088.Post-treatment, cells were washed with PBS, fixed in 4\% PFA for $10 \mathrm{~min}$ followed by permeabilization with $0.1 \%$ Triton $\mathrm{X}$ containing PBS (PBST). After permeabilization cells were washed and blocked with $10 \%$ goat serum, followed by incubation in primary antibody against hTDP-43 (1:1000) at room temperature overnight. Next morning, the cells were washed with PBST and incubated with the fluorochrome-conjugated secondary antibody (1:500) for $1 \mathrm{~h}$ at room temperature in dark. After secondary antibody incubation, cells were washed and incubated in DAPI for $60 \mathrm{~s}$. Following five washes cells were mounted and observed under a fluorescence microscope (Zeiss, Germany).

\section{Mouse models and drug treatment}

Transgenic mice expressing hTDP-43A315T or hTDP43G348C were used for the experiment. Randomly selected animals were used for IMS-088 or vehicle treatment groups. IMS-088 was developed and generously provided by IMSTAR therapeutics, Canada. The average age of the mice at the start of the treatment was 1 year (pathological stage). $30 \mathrm{mg} / \mathrm{kg}$ of body weight IMS-088 (by gavage) was given twice a day for 8 weeks. Animals in the vehicle group received equal volumes of buffered saline for the same durations. Post-treatment, we blindly split each group into different subgroups and used all the mice for further experiments (Additional file 5). The Animal Care Ethics Committee of Université Laval approved all in vivo experimental protocols. Experiments were carried out in accordance with the Guide for the Care and Use of Experimental Animals of the Canadian Council on Animal Care.
Passive avoidance and novel object recognition test

For passive avoidance test, the mice were first conditioned in a light-dark chamber with getting foot-electric shock when they enter in the dark chamber. Next day, one-trial passive avoidance was performed as described earlier [20] to check whether they avoid entering the dark chamber based on their memory function. The latency time for mice to enter the dark compartment was measured for the final test, with a cut-off time of $300 \mathrm{~s}$.

Novel object recognition is a 3-day test, as previously described [21], in a $20 \times 50 \times 30 \mathrm{~cm}$ Plexiglas box for 5 min per session. Briefly, on the first day of trial, the mice were kept it in the empty box to familiarize with the environment. On the second day, two similar objects were placed in the box for mice to familiarize with the objects. On the final day of test, one of the objects was replaced with a new object and then the time spent by mice on the new object was measured for the different groups to compare the cognitive performance.

\section{Immunohistochemistry and image analysis}

Mice were anesthetized by intraperitoneal injection using $10 \mu \mathrm{l} / \mathrm{gm}$ pentobarbital $12 \mathrm{mg} / \mathrm{ml}$. The animals were transcranial perfused with ice cold phosphate buffered saline and $4 \%$ Paraformaldehyde. Post-perfusion brains and spinal cords were excised and post-fixed overnight in $4 \%$ PFA at $4{ }^{\circ} \mathrm{C}$. For cryoprotection brains and spinal cords were kept in $30 \%$ sucrose solution at $4{ }^{\circ} \mathrm{C}$ for a day and $25 \mu \mathrm{m}$ sections were cut using a sliding VT $1200 \mathrm{~S}$ vibratome (Leica Microsystems). Further the sections were mounted on the glass slides to procced with immunohistochemistry.

Section containing slides were washed three times with PBS (5 min) at room temperature and then antigen retrieval was performed for $20 \mathrm{~min}$ at $98^{\circ} \mathrm{C}$ using $6 \mathrm{M}$ sodium citrate buffer. Slides were washed with $1 \mathrm{X}$ PBS after to room temperature. The sections were then washed in $0.25 \%$ Triton X-100 in PBS (PBST) (3 X 5 min) and then blocked for $1 \mathrm{~h}$ in $10 \%$ goat serum in PBST in at room temperature. The sections were then incubated with primary antibodies overnight at room temperature. Next morning the sections were washed $(3 \times 10 \mathrm{~min})$ with $0.25 \%$ Triton X-100 in PBS and incubated with desired secondary antibodies for $90 \mathrm{~min}$ at room temperature in a dark chamber. Prior to mounting sections were incubated with DAPI (1 min), treated with true black $(1 \mathrm{~min})$ and then washed $(3 \times 10 \mathrm{~min})$ with $0.25 \%$ Triton X-100 in PBS. Mounting was done onto glass slides using mounting media.

Fluorescent signal was detected using LSM 700 inverted confocal microscope (Zeiss) or Apotome (Zeiss). For each experiment, the best acquisition parameter has established considering the sections are not overexposed and the saturated signals can be avoided. 
For quantifying mean fluorescence intensities of iba1 signals, at least 5-7 images per mice were captured at 20X using z-stack imaging method with Zeiss confocal microscope. We considered hippocampus and cortex separately as region of interest for analysis. Further, the quantification was performed using ImageJ software with the maximum intensity projection image. The average values were compared between saline and drug treated group. The data was represented as mean + standard error of mean (sem.)

\section{DNA constructs, generation of transgenic mice and genotyping}

The DNA construct used for the generation of the NFLHA-mRFP1-RPL10a transgenic mice were prepared as following. First, HA-mRFP1 fragment was obtained by PCR using the following primers: $5^{\prime}$ primer: $5^{\prime}$-GGG ACG ACG AAT TCG GAG GCA GCA TGT ACC CAT ACG ATG TTC CAG ATT ACG CTG CCT CCT CCG AGG ACG T-3' and 3' primer: 5'-GGG ACG ACG GAT CCG GCG CCG GTG GAG TGG CGG CCC-3' .

Then, the amplified fragment was introduced into pBluescript $\mathrm{KS}+$ plasmid into corresponding restriction sites. A $2.5 \mathrm{~Kb}$ BamHI /NotI fragment corresponding to the genomic DNA of 60s ribosomal protein L10a (RPL10a) was introduced into corresponding restriction sites of pBSKS-HA-mRFP1 recombinant vector. A 3.4 $\mathrm{Kb}$. XhoI/Xhol fragment corresponding to the HAmRFP1-mRPL10a transgene was introduced into pSKhNF-L plasmid instead of the exon 1. As described in Charron G. et al., 1995 [22], this plasmid contains human NF-L gene including - 292 bp of $5^{\prime}$ flanking sequences and intron sequences sufficient to drive NF-L expression in the nervous tissues of adult transgenic mice. To facilitate the digestion of the transgene, a KpnI restriction site was added to the PSKhNF-L plasmid at the position $6711 \mathrm{bp}$. The integrity of the final construct was verified by sequencing.

For microinjection, a KpnI-KpnI DNA fragment of 9.0 $\mathrm{kb}$ was isolated on agarose gel and purified using a QIAquick Gel Extraction Kit (Qiagen \#28115). The transgenic mice NFL-HA-mRFP1-RPL10a named NFLrRFP were viable, did not develop overt phenotypes and were genotyped by PCR amplification. For genotyping, a 179 bp fragment from the mRFP1 gene is amplified from the NFLrRFP transgenic mice and not from the wild type mice. The PCR was performed on ear punch samples using the $5^{\prime}$ mRFP1-GEN primer: 5'-GACCGCCAAG CTGAAGGTGA-3' and the $3^{\prime}$ ' mRFP1-GEN primer: $5^{\prime}$ CCGTCCTCGAAGTTCATCAC-3'.

The experiments presented in this paper were obtained by using the double transgenic mice named NFLrRFP;hTDP-43 A315T generated by crossing the NFLrRFP transgenic mice with our TDP43 ${ }^{\text {A315T }}$ mice (supplementary figure 1B). All experimental procedures were approved by the Laval University animal care ethics committee and are in accordance with The Guide to the Care and Use of Experimental Animals of the Canadian Council on Animal Care.

\section{Protein extraction and immunoblotting}

Both tissue and cell samples were lysed using RIPA buffer supplemented with protease inhibitor cocktail (Sigma, USA). Protein concentration was measured using Bradford reagent (Sigma, USA). $20-30 \mu \mathrm{g}$ of protein samples were loaded and separated using SDSPAGE followed by wet transfer on a methanol charged PVDF membrane. The membrane was blocked using 5\% Bovine serum albumin for an hour at room temperature and incubated with primary antibodies overnight at $4{ }^{\circ} \mathrm{C}$. The primary antibodies used at 1:1000 concentration were mouse monoclonal hTDP-43 (Abnova, Taiwan), LC3 (Novus Biologicals, USA), Beclin-1 (Novus Biologicals, USA), p62 (Millipore, USA), ATG-5 (Millipore, USA), and Actin (Millipore, USA), GFAP (Cell signalling technologies, USA),. Subsequently, the blots were incubated with either HRP-conjugated anti-rabbit or antimouse secondary antibodies. Moreover, the blots were developed using ECL detection reagents and visualized with a StarBright Blue 520 (Bio-Rad Laboratories, USA). All band intensities were quantified using the ImageJ lab software. The membranes were incubated with suitable peroxidase conjugated secondary antibodies (Vector Laboratories, USA). Once the incubation was over, PBST wash was given to the blots. Blots were then treated with ECL reagent and developed using UNITECH imaging system (Cambridge) from Millipore, CA USA.

\section{TRAP protocol}

TRAP protocol described by Heiman and colleagues with small modifications was used for the study [23, 24]. Cortex and hippocampal tissue were extracted from the brain and homogenized $(10 \% \mathrm{w} / \mathrm{v})$ together in tissue lysis buffer. The samples were centrifuged at $2000 \mathrm{~g}$ for 10 min at $4{ }^{\circ} \mathrm{C}$. Post-centrifugation, $1 / 9$ sample volume of $10 \% \mathrm{NP}-40$ and $1 / 9$ sample volume of $300 \mathrm{mM}$ DHPC were added to the supernatant. Further the sample was gently mixed and then incubated for $30 \mathrm{~min}$ at $4{ }^{\circ} \mathrm{C}$ on orbital shaker. Post-incubation, centrifugation at 20,000 $\mathrm{g}$ for $10 \mathrm{~min}$ was given at $4{ }^{\circ} \mathrm{C}$. The supernatant was further collected and divided into two equal volume parts (one part was used for mRNA isolation and the other for peptide extraction). Each sample was added to the anti-RFP agarose affinity resin and incubated overnight at $4{ }^{\circ} \mathrm{C}$ on orbital shaker. Next day, the beads were isolated using centrifugation and washed 4 times using high-salt buffer (20 mM HEPES-KOH [pH 7.3], $350 \mathrm{mM}$ $\mathrm{KCl}, 12 \mathrm{mM} \mathrm{MgCl} 2,1 \% \mathrm{NP}-40,0.5 \mathrm{mM}$ DTT, and 100 
$\mathrm{mg} / \mathrm{mL}$ cycloheximide. The beads pellet was used either for mRNA purification or peptide purification.

\section{Purification of mRNA after TRAP protocol}

After the last washing, the beads were resuspended in $100 \mu \mathrm{L}$ Nano prep lysis buffer with betamercaptoethanol for $10 \mathrm{~min}$ at room temperature. The RNA isolation was performed according to the kit manufacturer's instructions (Absolutely RNA Nano prep kit). Three biological replicates were performed for each experiment (for each replicate, $n=2$ ). Purified isolated RNA was subjected to Affymetrix mouse gene chip.

\section{Purification of peptides after TRAP protocol}

At the end of washing, beads were resuspended in EDTA-elution buffer (10 mM HEPES-KOH [pH 7.3], $150 \mathrm{mM} \mathrm{KCl}, 5 \mathrm{mM} \mathrm{MgCl} 2,20 \mathrm{mM}$ EDTA, and protease inhibitors) and incubated for $30 \mathrm{~min}$ at room temperature on orbital shaker. EDTA elution buffer was used to dissociate ribosomes and release nascent chain peptides. Eluate was recovered by centrifugation at 7000 rpm for $15 \mathrm{~min}$. Collected ribosome associated peptides were sequenced by mass spectrometry using Orbitrap fusion mass spectrometer. Three biological replicates were performed for this experiment $(n=6$ per condition).

\section{Statistical analysis}

Prism 5.0 software (GraphPad, La Jolla, CA, USA) was used for all statistical analysis. Comparisons between 2 groups were done by unpaired two-tailed $t$ test. Comparison between multiple groups was done by 1-way analysis of variance with Bonferroni's or turkey post-test. A $p$-value up to 0.05 was considered significant.

\section{Results}

IMS-088 treatment inhibits NF-KB activation in vitro

The NF- $k B$ pathway is one of the major pathways which regulates neuroinflammation and can be activated by different inflammatory insults including bacterial lipopolysaccharide or TNF- $\alpha$. To test the NF- $\mathrm{kB}$ inhibitory potential of IMS-088, we primed BV2 cells (microglial cell line) stably transfected with NF-kB-P65-luciferase reporter with LPS for $2 \mathrm{~h}$ after which the cells were exposed to varying concentrations of IMS-088 or WFA. We found significant 4-fold upregulation in NF-kB activity in LPS-treated group in comparison to DMSO treated group (Fig. 1a). Treatment with varying concentration of IMS-088 or WFA reduced the LPS-induced NF- $\mathrm{KB}$ activity in BV2 cells in a dose-dependent manner between 1 to $5 \mu \mathrm{M}$ (Fig. 1a). Further to test the anti-NF$\kappa B$ property of IMS- 088 in neuronal cells, we treated NSC-34 cells stably transfected with NF-кB P65-luciferase reporter with TNF $\alpha(40 \mathrm{ng} / \mathrm{ml})$ for $4 \mathrm{~h}$. Then, the cells were exposed to IMS-088 or WFA $(1 \mu \mathrm{M})$. There was a significant increase of 1.5 -fold in NF- $\mathrm{kB}$ activity after TNF- $\alpha$ treatment whereas post-treatment with IMS-088 or WFA caused significant reduction of 3 folds in NF- $\mathrm{KB}$ activity (Fig. 1b). No cell loss was detected in any of the treatment groups except a 30\% loss of BV2 cells treated with IMS-088 or WFA at $5 \mu \mathrm{M}$ in LPScontaining media (Fig. 1b, d).

\section{IMS-088 treatment reduces ethacrynic acid-induced TDP-} 43 proteinopathy in cultured cells

It has been reported that ethacrynic acid (EA) treatment to cultured cells mimics the TDP- 43 proteinopathy in vitro [25]. We used this paradigm to test in vitro therapeutic potential of IMS-088. We treated HEK293 cells overnight with $50 \mu \mathrm{M}$ of EA in the presence or absence of IMS-088 $(1 \mu \mathrm{M})$. Immunofluorescence microscopy and immunoblot revealed that treatment with EA significantly induced the cytoplasmic mis-localization of TDP-43 in comparison to the control DMSO- treated group. Remarkably, the presence of IMS-088 in the media resulted in a $\sim 50 \%$ reduction of cells exhibiting cytoplasmic mis-localization of TDP-43 (Fig. 2a, b, c). Further, immunoblot of RIPA insoluble and soluble fractions revealed that the presence of IMS-088 in the media reduced the EA-induced aggregation of TDP-43 in cells (Fig. 2d, e). No cell loss was observed in any of the treatment groups (Fig. 2f).

\section{IMS-088 improved cognitive performance of transgenic mice expressing hTDP-43 mutants}

IMS-088 passes the blood-brain barrier. A pharmacokinetic study in mice with ${ }^{14} \mathrm{C}$-IMS-088 given orally revealed that ${ }^{14} \mathrm{C}$-radioactivity loss from plasma occurred with a half-life of $\sim 35 \mathrm{~h}$ while the radiolabel disappeared from the brain with a half-life of $\sim 213 \mathrm{~h}$.

A dose of IMS-088 (30 mg/kg body weight) was administered orally (gavage) twice a day for 8 weeks to hTDP-43 ${ }^{\mathrm{A} 315 \mathrm{~T}}(n=19)$ and hTDP-43 ${ }^{\mathrm{G} 348 \mathrm{C}}(n=8)$ transgenic mice staring at $\sim 12$ months of age. The control hTDP-43 ${ }^{\mathrm{A} 315 \mathrm{~T}}(n=18)$ and hTDP-43 ${ }^{\mathrm{G} 348 \mathrm{C}}(\mathrm{n}=8)$ mice received equal volumes of buffered saline. The treatment of IMS-088 or saline for 8 weeks had no effects on viability or body weight of animals. Post treatment, mice were subjected to passive avoidance and novel object recognition tests to assess cognitive functions. In the passive avoidance test, analysis revealed that the salinetreated hTDP- $43^{\mathrm{A} 315 \mathrm{~T}}$ and hTDP- $43^{\mathrm{G} 348 \mathrm{C}}$ mouse often failed to recollect the foot shock during the training session with average latency to cross the dark chamber of $135.3 \pm 25.80 \mathrm{~s} ; N=18$ and $184.2 \pm 45.01 \mathrm{~s} ; N=8$ respectively. IMS-088 treatment significantly increased the latency of hTDP- $43^{\mathrm{A} 315 \mathrm{~T}}$ and hTDP-43 ${ }^{\mathrm{G} 348 \mathrm{C}}$ mice to enter in the dark chamber with retention time between 


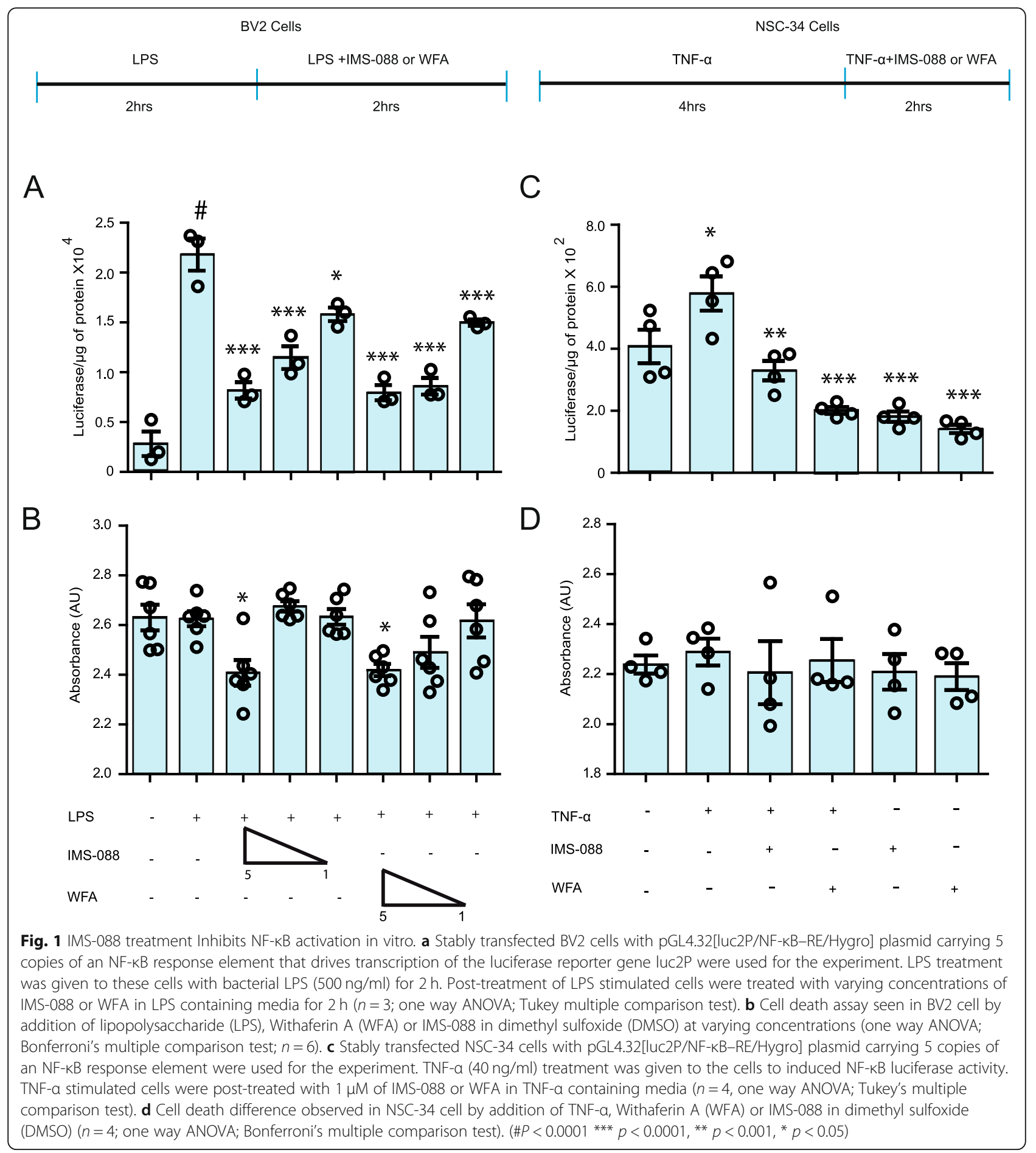

$209.3 \pm 21.82 \mathrm{~s} ; N=19$ and $291.3 \pm 6.325 \mathrm{~s} ; \mathrm{N}=8$ respectively (Fig. 3a, b). For instance, majority of the IMS-088treated hTDP-43 ${ }^{\mathrm{G} 348 \mathrm{C}}$ mice $(75 \%)$ scored $300 \mathrm{~s}$ whereas only $25 \%$ of the control hTDP- $43^{\mathrm{G} 348 \mathrm{C}}$ mice scored 300 s. Further to assess temporal lobe-dependent memory function, the novel object recognition test was performed. During the training session, no difference was observed in behavior between the IMS-088-treated and the saline-treated groups. After the training session, we performed the choice phase test in which the IMS-088treated mice expressing hTDP-43 mutants showed significant increase in the time spent with the novel object (65 to $70 \%$ time) in comparison to saline-treated control mice ( 45 to $50 \%$ time) (Fig. 3c, d). 

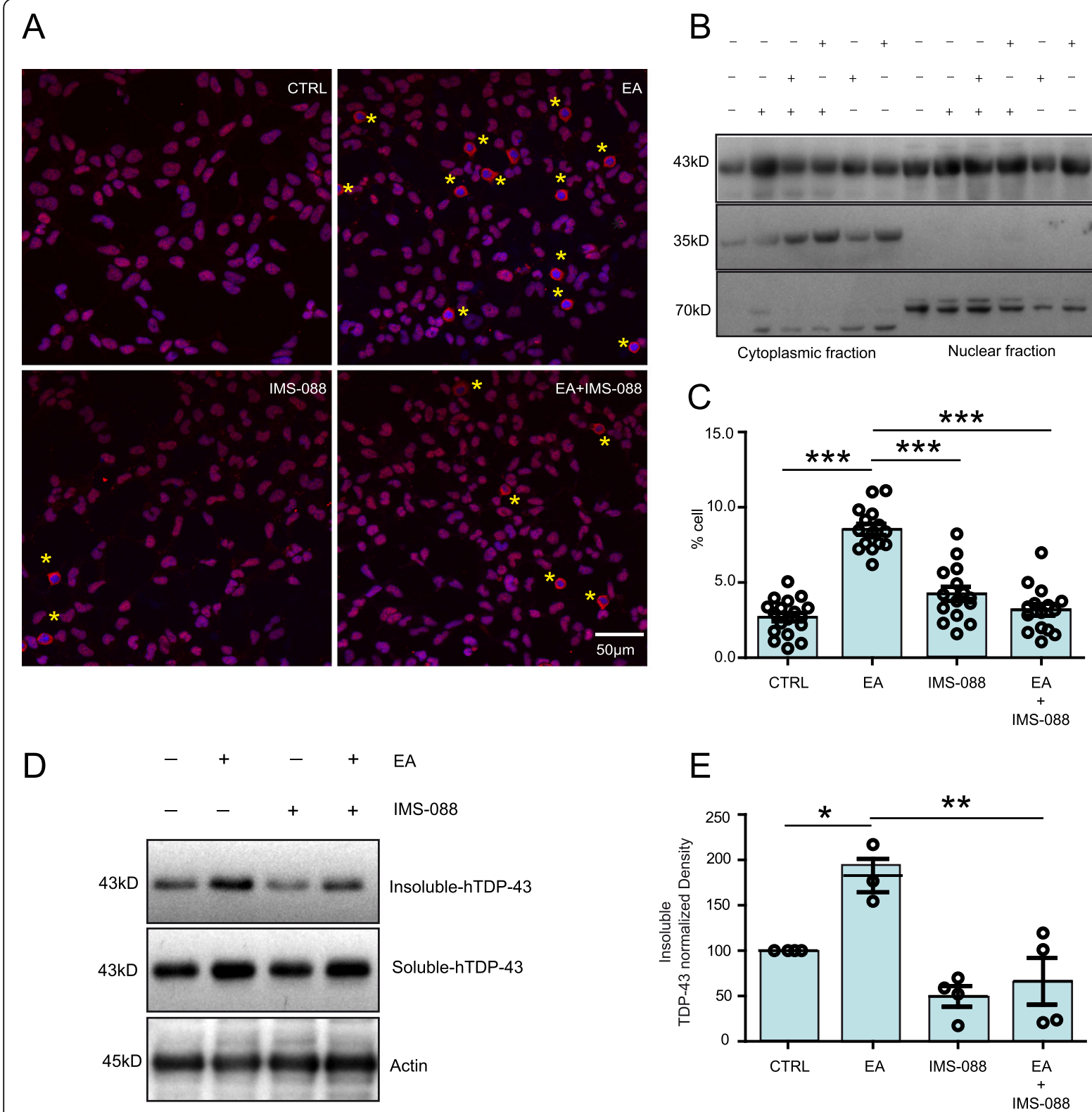

E

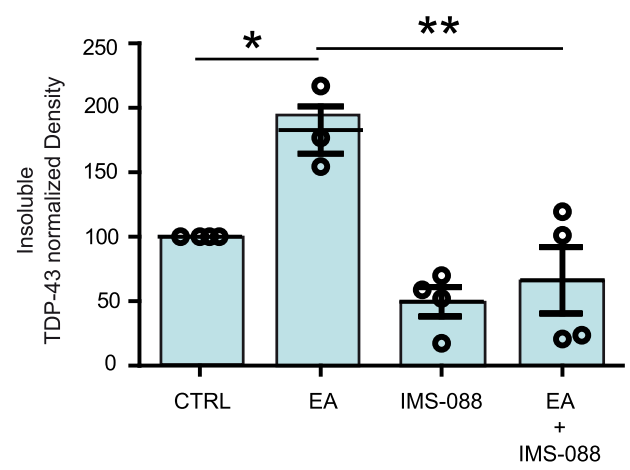

$\mathrm{F}$
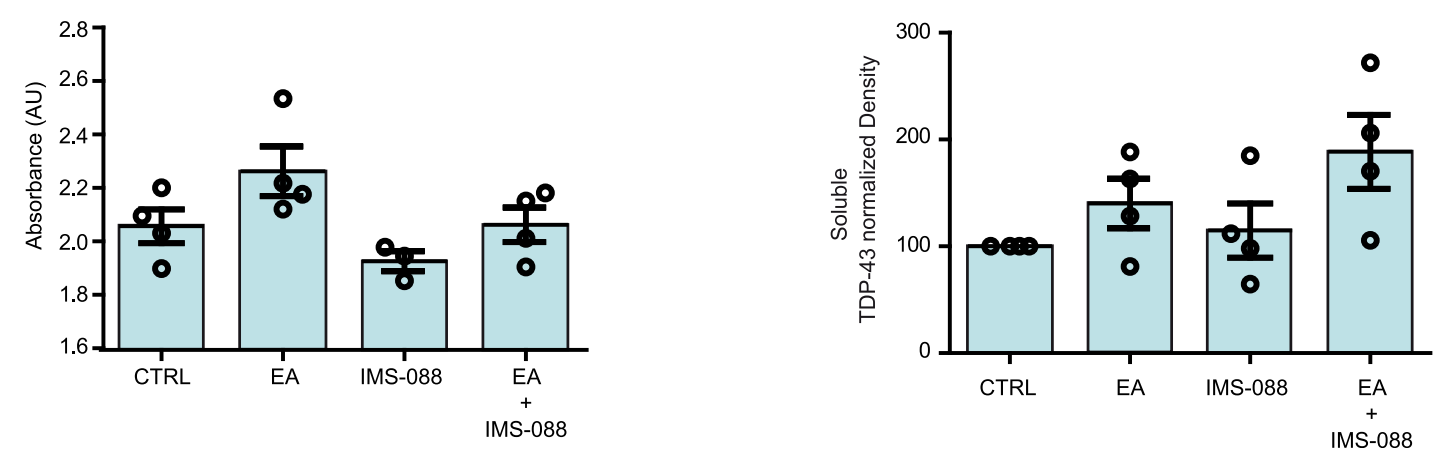

Fig. 2 (See legend on next page.) 
(See figure on previous page.)

Fig. 2 IMS-088 treatment reduces ethacrynic acid-induced TDP-43 proteinopathy in cultured cells. a Representative immunostaining and (b) immunoblot showing ethacrynic acid treatment induced cytoplasmic TDP-43 in HEK293 cells. Presence of IMS-088 in the media has reduced the cytoplasmic mis-localization in the cells. Pictures represent merge of hTDP-43 (red) and Hoechst (nuclei, blue) channels, Scale bar $=50 \mu \mathrm{m}$. c Data are represented as \% cells showing TDP-43 cytoplasmic mis-localization [15] frames were analysed from 3 independent experiments). Data were analyzed by 1-way ANOVA with Bonferroni's multiple comparison test as the post-test ( ${ }^{* * *} P<0.0001$ ). $\mathbf{d}$ Immunoblot and (e) quantification of RIPA soluble or insoluble TDP-43 in Hek293 cells received different treatments. ( $n=3-4$; 1 -way ANOVA with Bonferroni's multiple comparison test as the post-test). $\mathbf{f}$ Data showing cell survival assay difference observed in different treatment groups $(n=4 ; 1$-way ANOVA with Bonferroni's multiple comparison test as the post-test). Graphs show mean \pm sem

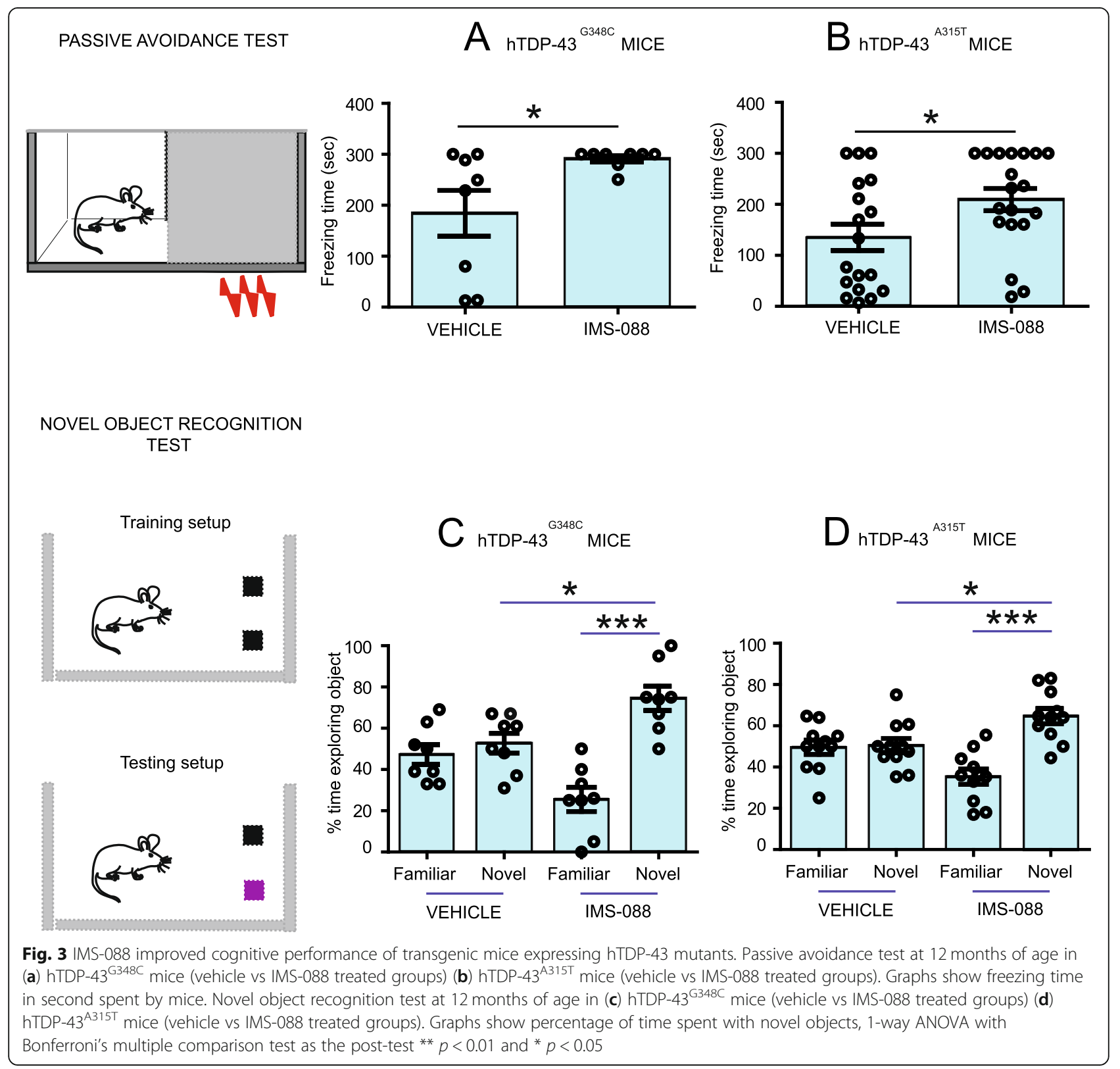




\section{IMS-088 treatment reduced microglial and astrocyte activation in mutant hTDP-43 mice}

Since mutant hTDP-43 mice shows NF-kB induced inflammation, we tested anti-inflammatory properties of IMS-088. Immunofluorescence microscopy of brains sections was carried out using antibodies for detection of glial fibrillary acidic protein GFAP (astrocyte marker) and iba1 (microglial markers). As shown in Fig. 4a and b, IMS-088 treatment significantly reduced the immunostaining of iba1 protein in the microglia in cortex and hippocampus of the mice brain in compared to the saline-treated mice. Morphologically, more microglia were in reactive state occupying significantly larger area in the brain of vehicle-treated mice in comparison to IMS-088-treated mice. In IMS-088-treated group, the microglia exhibited small cell soma with distal arborisation in contrast to microglia in vehicle-treated mice which had large cell body with short thick processes.

In addition, immunoblot analysis revealed significant reduction in GFAP protein levels without changing the total TDP-43 levels in the IMS-088-treated group in comparison to vehicle-treated group. Consistent with reduction of astrocytosis, immunofluorescence revealed that morphologically the GFAP+ cells had thick processes and large cell body in vehicle-treated mice whereas the GFAP+ cells in the IMS-088- treated group were smaller (Fig. 4c, d).

\section{IMS-088 treatment reduced cytoplasmic TDP-43 aggregates}

During aging, hTDP-43 $3^{\mathrm{A} 315 \mathrm{~T}}$ and the hTDP-43 ${ }^{\mathrm{G} 348 \mathrm{C}}$ transgenic mice develop cytoplasmic mis-localization and aggregation of TDP-43 in neurons [12]. We have examined the effect of 8-week treatment with IMS-088 on the distribution and aggregation of hTDP-43 in the brain cortex region. Immunofluorescence microscopy in (Fig. 5a) revealed abundant hTDP-43 aggregates in the cytoplasm of cortical NeuN+ cells in saline-treated hTDP-43 ${ }^{\text {A315T }}$ mice at 1 year of age. Remarkably, treatment with IMS-088 restored the nuclear localization of TDP-43 and it substantially eliminated the presence of hTDP-43 aggregates. Consistent with the microscopy data, immunoblotting revealed decreases of 3 to 4 folds in levels of hTDP-43 recovered in the RIPA insoluble protein fractions of the brain (Fig. 5b). In contrast, the levels of soluble hTDP-43 in the brain did not differ significantly between IMS-088-treated and saline-treated mice expressing hTDP-43 mutants (Fig. 5b). Note that $35 \mathrm{kD}$ and $25 \mathrm{kD}$ fragments of TDP-43 were not detected in these experiments using the anti-human TDP-43 antibody. Interestingly, our data also revealed that in addition to insoluble level of hTDP-43, IMS-088 treatment has also significantly reduced the total level of
phospho-TDP 43 by more than 2 folds in the brain of hTDP-43A315T mice (Fig. S1A).

Further, we measured the cytoplasmic to nuclear ratio in the large motor neurons of the spinal cord. Interestingly, treatment of IMS-088 has significantly reduced the cytoplasmic localization of TDP-43 in motor neurons of the hTDP-43 ${ }^{\mathrm{G} 348 \mathrm{C}}$ mice (Fig. 5c). The combined data suggest that IMS-088 treatment has reduced TDP-43 proteinopathy in neurons.

\section{IMS-088 treatment boosted autophagy}

There is evidence suggesting that the inhibition of NF$\mathrm{\kappa B}$ signalling can potentially induce cellular autophagy [26]. Accordingly, we have investigated the effect of IMS-088 on levels of autophagic markers. After 8-week treatment with IMS-088, we detected a significant 2-fold increase in the levels of LC3BII, an autophagic marker, in comparison to vehicle-treated group (Fig. 6a, e). We also found an increase of $150 \%$ in Beclin-1, another autophagic marker, in the IMS-088-treated group (Fig. 6a, c). The levels of p62 and ATG5 remained unchanged (Fig. 6a, b, d). To further study IMS-088 mediated clearance of TDP-43 aggregates via autophagy, we blocked autophagosome-lysosome fusion using Bafilomycin A1 in HEK293 cells and analysed the levels of EA induced RIPA-insoluble and soluble TDP-43 levels. Immunoblot analysis has revealed a significant increased level of EAinduced RIPA insoluble-TDP-43 levels in IMS-088 with BafilomycinA1 treated group in comparison to IMS-088 alone (Fig. S2). We did not find any changes in RIPAsoluble level in any treated group (Fig. S2). From these results, we conclude that the IMS-088 treatment induced autophagic activity which may explain the clearance of cytoplasmic TDP-43 accumulations in brain and spinal neurons of TDP-43 $3^{\mathrm{A} 315 \mathrm{~T}}$ and TDP- $43^{\mathrm{G} 348 \mathrm{C}} \mathrm{mu}-$ tant mice.

\section{Translational suppression of neurofilament mRNAs in hTDP-43 ${ }^{\text {A315T }}$ mice}

Studies have shown that TDP-43 directly participates in regulation of translation [8-10]. TDP-43 proteinopathy in cells has also been shown to supress the global translation by interaction with RANK1 on polyribosome [11]. However, the impact of TDP-43 proteinopathy on neuronal translational profile in vivo remains unknown. Here, to investigate the molecular profiles of neuronal cells in vivo, we used a modified translational affinity purification (TRAP) and EDTA purified ribosomes associated nascent peptide chains (EDTA purified RANC) method [24]. This method involves the immunoprecipitation of the polyribosome complex with the attached mRNA and novel synthesizing peptides in a cell-specific manner from a complex tissue. To study the translational profile in neurons of the CNS, we have generated 


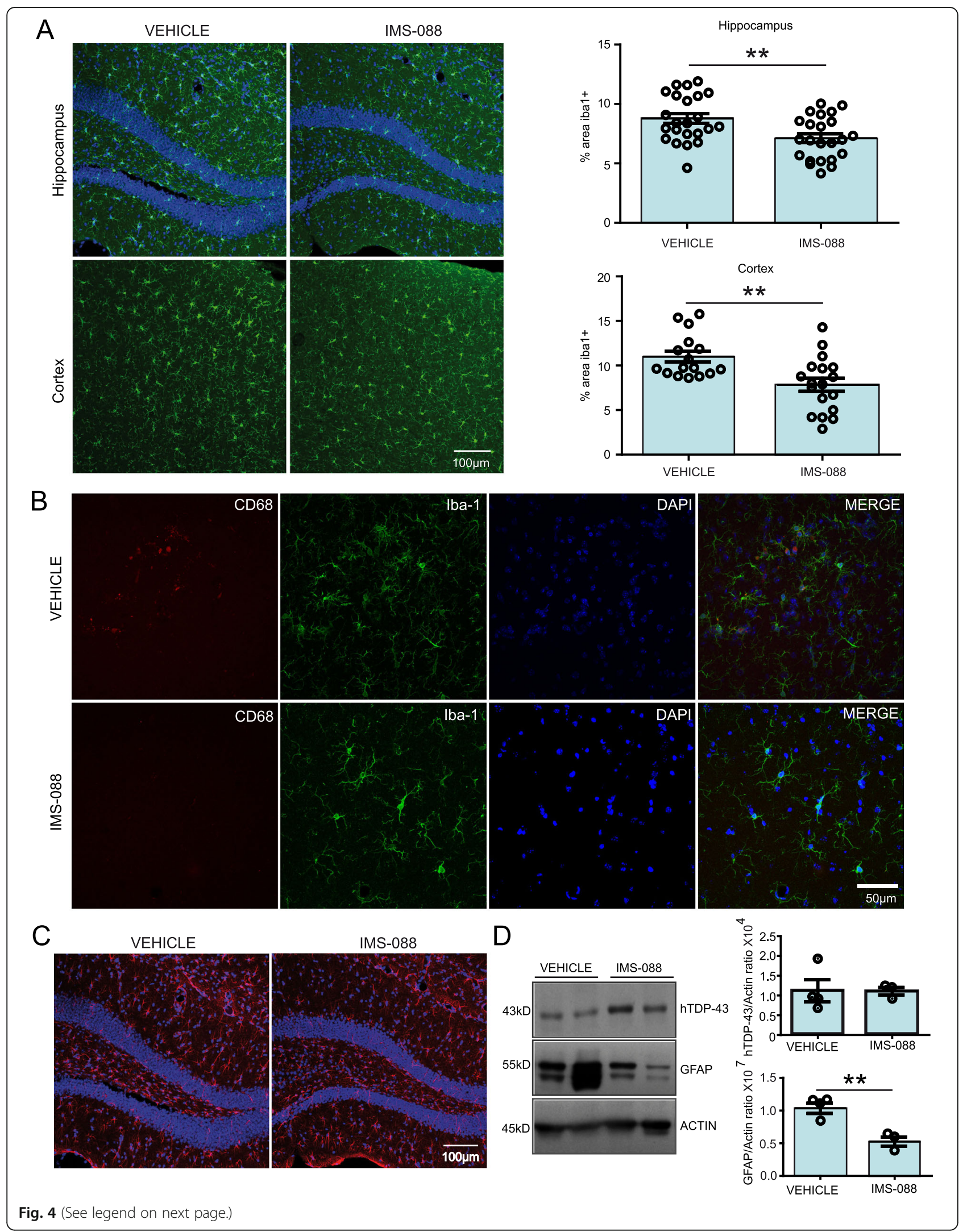


(See figure on previous page.)

Fig. 4 IMS-088 treatment reduced microglial and astrocyte activation in mutant hTDP-43 mice. a Representative immunostaining showing microglial cells in the cortex and hippocampal region of the hTDP-43 mutant mouse brains from the vehicle and IMS-088 treated groups. Graph presents quantification of $\%$ area covered by the iba1+ cells, using multiple sections from $n=3-4$ mice, unpaired t-test; * $p<0.05$. $\mathbf{b}$ Representative immunostaining of CD-68 + (red) and Iba1 (green) co-staining in vehicle and IMS-088 treated groups. c Representative image showing astrocytes in the hippocampal region of the hTDP-43 mutant mouse brains from the vehicle and IMS-088 treated groups. $\mathbf{d}$ Representing immunoblot and quantification of GFAP and total TDP-43 protein levels in the different treatment groups $(n=3-4)$. Graph represents the relative density of GFAP and total TDP-43 in the brain of vehicle and IMS-088 treated mice, unpaired t-test; ${ }^{* *} p<0.01$

a transgenic mouse model named NFL-rRFP which expresses HA-RFP1 tagged rpl10 ribosomal protein under the human NEFL promotor (Additional file 5, Fig. S3). To address the effects of TDP-43 pathology on neuronal translational profile, the NFL-rRFP mice were bred with hTDP-43 ${ }^{\mathrm{A} 315 \mathrm{~T}}$ mice to derive NFL-rRFP; hTDP-43 ${ }^{\mathrm{A} 315 \mathrm{~T}}$ transgenic mice (Additional file 5, Fig. S3). The neuronspecific expression of RFP1 in NFL-rRFP; hTDP-43 ${ }^{\mathrm{A} 315 \mathrm{~T}}$ mice was confirmed by immunofluorescence microscopy of brain sections using NeuN as neuronal marker (Additional file 5, Fig. S3C).

At 12 months of age when the NFL-rRFP;hTDP$43^{\text {A315T }}$ mice exhibited TDP-43 proteinopathy in cortical neurons, the brain tissue was collected for immunoprecipitation of ribosomes with anti-RFP antibody followed by purification and analyses of ribosome attached mRNA and newly synthesized peptides. The affymetrix Mouse Genome 430 analysis of mRNAs did not reveal significant changes for most of the genes. There was a differential regulation in only $0.13 \%$ mRNA bound to neuronal ribosomes in the NFL-rRFP;hTDP-43 ${ }^{\mathrm{A} 315 \mathrm{~T}}$ transgenic mice as compared to NFL-rRFP mice (Fig. 7a). Among the differentially regulated mRNAs, we found an upregulation of $80.23 \%$ mRNAs and a downregulation of $19.77 \%$ mRNAs in NF-L-RFP;TDP-43 ${ }^{\mathrm{A} 315 \mathrm{~T}}$ transgenic mice when compared to NFL-rRFP mice (Fig. 7a).

Further, mass spectroscopic analysis was performed with the EDTA-purified ribosomes associated nascent peptide chains isolated from ribosomal-complex immune-purification from brain neuronal cells. Interestingly, 117 different proteins exhibited significant changes in neuronal expression levels for NFL-rRFP;hTDP$43^{\mathrm{A} 315 \mathrm{~T}}$ mice versus age-matched NFL-rRFP mice (Fig. 7b). Gene ontology (GO) functional analysis with upregulated peptides using David6.8 has revealed an upregulation in the metabolic pathways including mitochondrial function (Fig. S4A). In addition, levels of several peptides were highly increased in NFL-rRFP;hTDP-43 ${ }^{\text {A315T }}$ mouse brain including Pin1 (peptidyl-prolyl cis-trans isomerase) which was approximately 5 folds higher than in samples from NFL-rRFP mice (Fig. S4D). Mitochondria-localized Pin1 has been reported to serve as a molecular switch that couples the phosphorylation of components of the apoptotic machinery to cell death processes, specifically in neurons.
Conversely, GO functional analysis with David software of the downregulated peptides revealed neuronal cytoskeletal disorganisation including a prominent down-regulation of neurofilament peptides in NFL-rRFP; hTDP-43 ${ }^{\text {A315T }}$ mouse brain samples (Fig. 7c). Thus, levels of neurofilament peptides such as Nefl, NefM and $\alpha$-internexin were decreased by 3.5 to 4 folds in NFLrRFP;hTDP-43 ${ }^{\mathrm{A} 315 \mathrm{~T}}$ mice as compared to NFL-rRFP mice (Fig. 7e). Further, analysis of ribosome bound mRNA levels of Nefl, NefM and $\alpha$-internexin has not shown any changes (Fig. 7d). The divergence of mRNA and protein levels data suggest that cytoplasmic TDP-43 accumulations in hTDP- $43^{\mathrm{A} 315 \mathrm{~T}}$ mice cause translational suppression of neurofilament protein synthesis. Note that other downregulated peptides were also significantly downregulated in hTDP-43 $3^{\mathrm{A} 315 \mathrm{~T}}$ mice brain neurons and their expression levels restored by IMS-088 treatment (Fig. S4D). For these other downregulated peptides in neuronal ribosomes of hTDP-43 mice there was no corresponding decreases in levels of ribosome-bound mRNA. This indicated that there was a translational blockade of these mRNA species.

\section{IMS-088 treatment reversed the neuronal translational defects associated with TDP-43 proteinopathy}

To test the effects of IMS-088 on brain neuronal translational profiles, vehicle or IMS-088 $(30 \mathrm{mg} / \mathrm{kg})$ was administered twice-per-day for 8 weeks using gavage to NFL-rRFP;hTDP-43 ${ }^{\mathrm{A} 315 \mathrm{~T}}$ mice starting at approximately 10 months of age. In Affymetrix Mouse Genome 430 analysis, we found significant changes in only $4.13 \%$ of the mRNAs related to IMS-088 treatment (Fig. 8a). Among this $4.13 \%$ mRNAs, $56.09 \%$ mRNAs were upregulated whereas $43.91 \%$ mRNAs were downregulated in the upregulated mRNA group, $17.07 \%$ mRNAs were non-coding while in the downregulated mRNA group, $59.15 \%$ of genes were non-coding with unknown function (Additional file 5, Fig. S4C).

Mass spectroscopy analysis revealed that IMS-088 treatment of NFL-rRFP; hTDP-43 ${ }^{\mathrm{A} 315 \mathrm{~T}}$ mice significantly altered the synthesis of 199 different neuronal proteins (Fig. 8b). Of particular interest was the finding that IMS088 treatment reversed the translational block of neurofilament mRNAs (Fig. 8c, e). Thus, the most prominent upregulation changes due to IMS-088 treatment of NFL- 

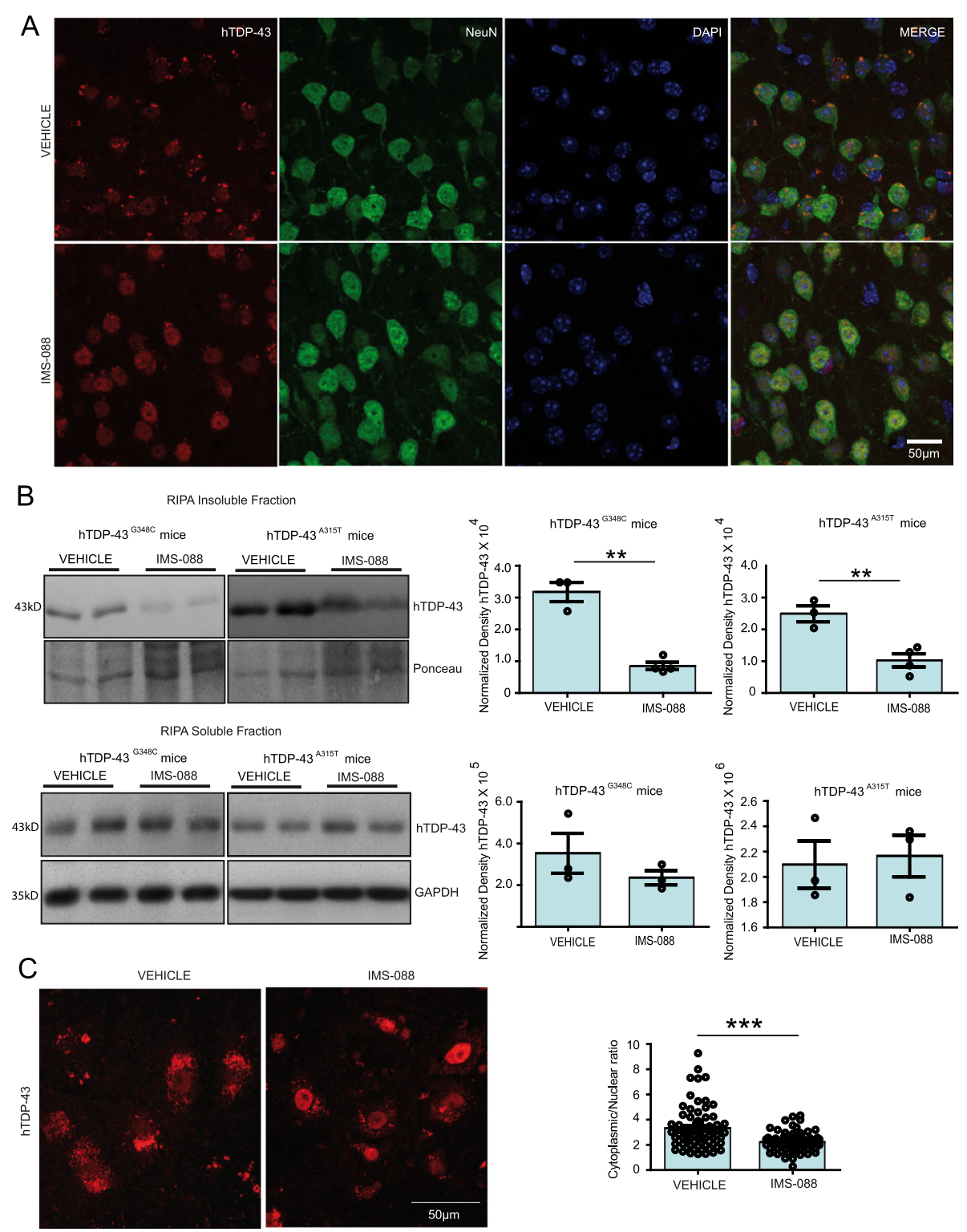

Fig. 5 IMS-088 treatment reduced cytoplasmic TDP-43 aggregates in mutant hTDP-43 mice. a Representative pictures showing TDP-43 (red), NeuN (green) and DAPI (blue) in brain sections of vehicle and IMS-088 treated hTDP-43 mutant transgenic mice. b Representative immunoblots and quantification of RIPA insoluble and RIPA soluble fractions of brain from $n=3-4$ independent mice from both hTDP-43 ${ }^{\mathrm{G} 348 \mathrm{C}}$ and $\mathrm{hTDP}$ $43^{\mathrm{A} 315 \mathrm{~T}}$ mice. The TDP-43 was normalized with ponceau or GAPD H. c Representative images and graph showing the cytoplasmic hTDP-43 in spinal motor neurons by IMS-088 treatment and the quantification of cytoplasmic to nuclear ration of hTDP-43 in hTDP-43 $3^{\mathrm{G} 348 \mathrm{C}}$ mice $(n=75$ neurons from 3 mice each group. Statistical analysis used was unpaired T-test. Data represents mean \pm sem. ${ }^{* *} p<0.01 ;{ }^{* * *} p<0.001$

rRFP; hTDP-43 ${ }^{\mathrm{A} 315 \mathrm{~T}}$ mice were the 6 to 8 -fold increase in neurofilament peptides such as Nefl, Nefm and $\alpha$ internexin (Fig. 8e). The restoration of neurofilament protein synthesis by IMS-088 treatment in NFL-rRFP; hTDP-43 ${ }^{\mathrm{A} 315 \mathrm{~T}}$ mice was further confirmed by immunoblot analysis (Fig. 8f). In addition to neurofilaments, IMS-088 restored expression levels of specific peptides related to mRNA splicing, neurite outgrowth or apoptosis. As shown in Supplementary Fig. S4D, IMS-088 restored the levels of most peptides whose levels were deregulated in hTDP-43A315T mice. For instance, the levels of Pin1, srsf3 and camk4 were restored by IMS088 treatment (Fig. S4D). Interestingly, apoptotic protein Pin1, which is upregulated in NFL-rRFP; hTDP-43 ${ }^{\mathrm{A} 315 \mathrm{~T}}$ mice was downregulated by 7.5 folds after IMS-088 treatment (Fig. S4D).

These mRNA and proteomic data provided evidence for neuroprotective effects of IMS-088. A most remarkable outcome of IMS-088 treatment was the restoration of synthesis of neurofilament proteins which were 


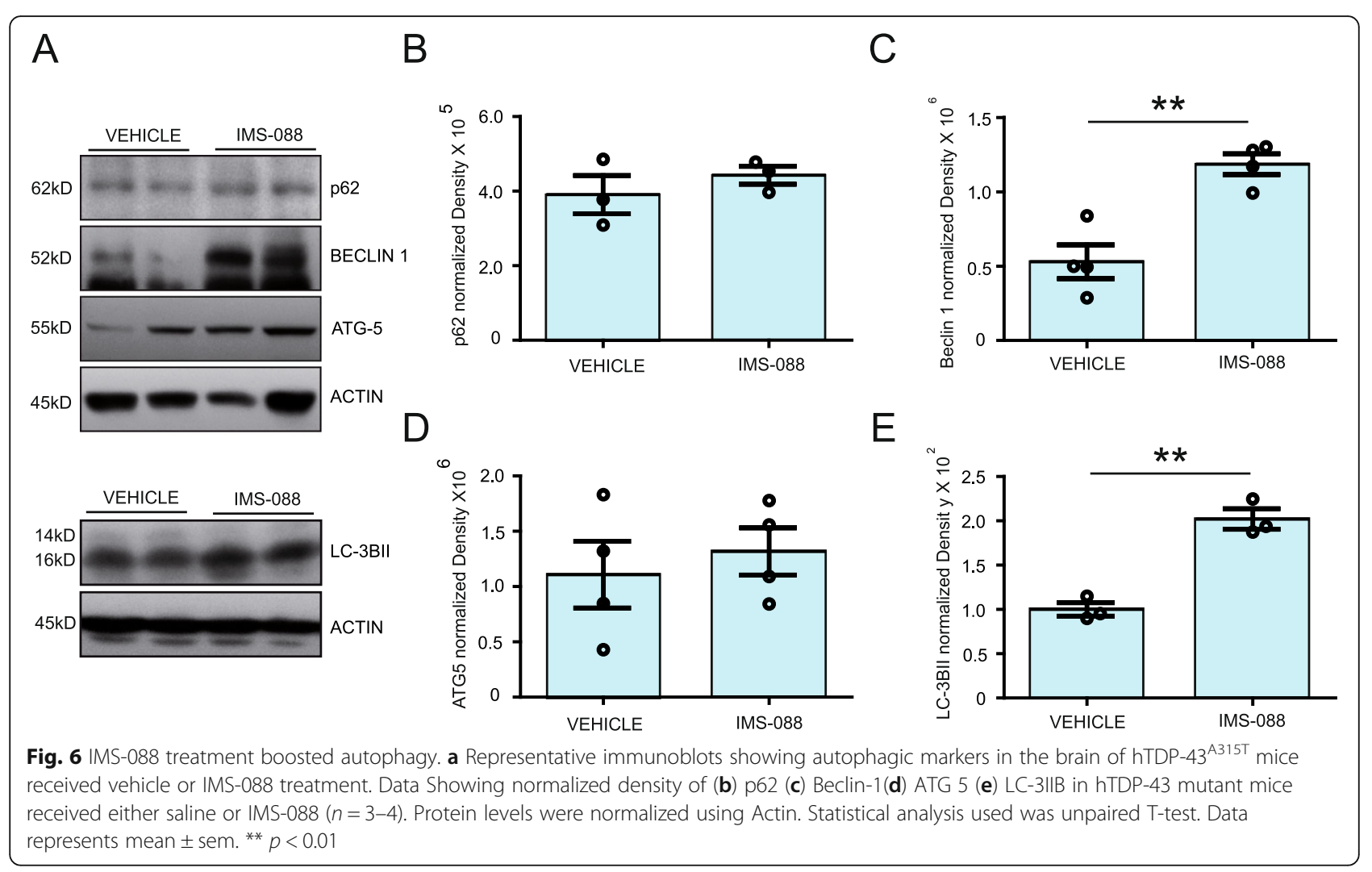

subjected to translational suppression in context of cytoplasmic TDP-43 mis-accumulation in hTDP$43^{\mathrm{A} 315 \mathrm{~T}}$ mice.

\section{Discussion}

TDP-43 aggregates in motor neurons are found in the majority of ALS patients [27]. TDP-43 aggregates are also found in other neurodegenerative diseases including LATE [28] and 50\% patients of FTD and Alzheimer's disease $[6,7]$. TDP-43 protein is involved in the regulation of RNA processing and splicing [1] as well as in chromatin condensation [2]. However, the impact of cytoplasmic TDP-43 mis-accumulation on mRNA translation in vivo has remained unknown. Here we used a Ribotag method [24] in combination with mass spectrometry to study the translational profiles of neurons in one-year old transgenic mice expressing ALS-linked hTDP-43 ${ }^{\text {A315T }}$ mutant, a model of ALS/FTD [12]. Our study revealed for the first time that TDP-43 proteinopathy can cause translational deregulation of specific mRNAs. Remarkably, GO functional analysis indicated substantial suppression of mRNA translation for neurofilament Nefl, Nefm and $\alpha$-internexin in hTDP-43 ${ }^{\text {A315T }}$ mice. Neurofilaments are major cytoskeletal components in neurons. Transgenic mouse studies have highlighted the importance of neurofilament protein stoichiometry for correct assembly and transport [29-32].
Neurofilament disorganization can contribute to neuronal dysfunction and death [30,33]. Reduced expression of Nefl or Nefm proteins has been shown to cause defect in synaptic function with ensuing behavioral impairment $[34,35]$. Previous reports showed that TDP-43 can bind and stabilize neurofilament mRNAs [2, 36]. Here, our results suggest that cytoplasmic accumulations of TDP-43 can result in a gain of toxic function involving deregulation of mRNA translation and especially suppression of neurofilament protein synthesis. Our data did not reveal any changes in the levels of ribosome-bound mRNA of Nefl, Nefm, and alfa-internexin but they showed reduced levels of novel synthesizing peptides for these genes, suggesting translational blockage (Fig. 7d, e).

We report here the therapeutic effects of a novel withaferin-A analog, called IMS-088, in transgenic mice expressing hTDP-43 mutants. Withaferin-A, a compound extracted from the medicinal plant Withania somnifera has emerged with a therapeutic potential as inhibitor of NF- $\mathrm{KB}$ signalling pathway via NEMO interaction [19] and as inducer of autophagy [37]. Withaferin-A treatment conferred protection in two mouse models of ALS [16, 38]. Furthermore, .withaferinA treatment of a mouse model of cerebral ischemia led to amelioration of pathological changes with reduction in NF-kB-mediated inflammation [39]. Despite beneficial properties of withaferin- $\mathrm{A}$, this compound can induce 

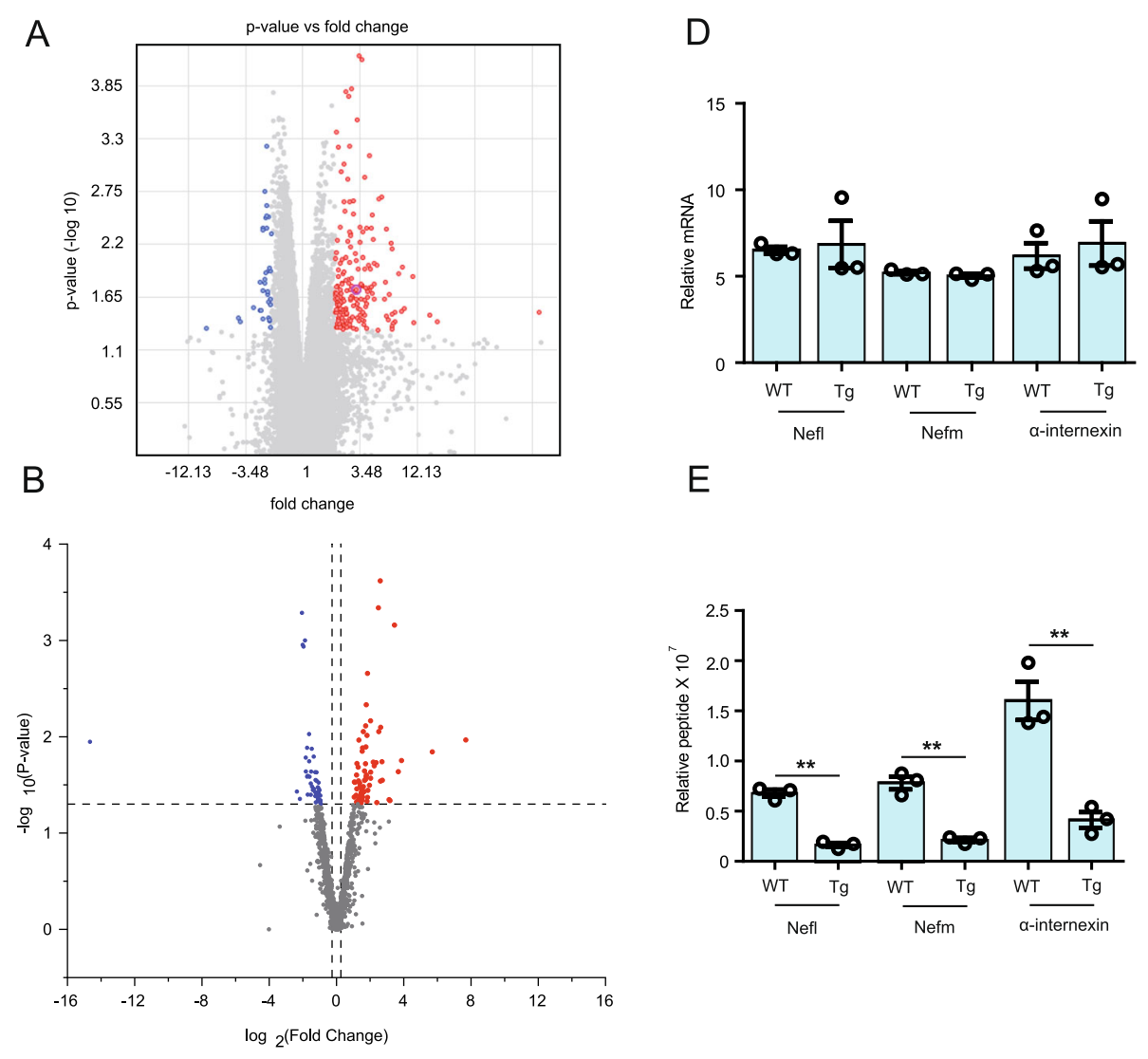

E
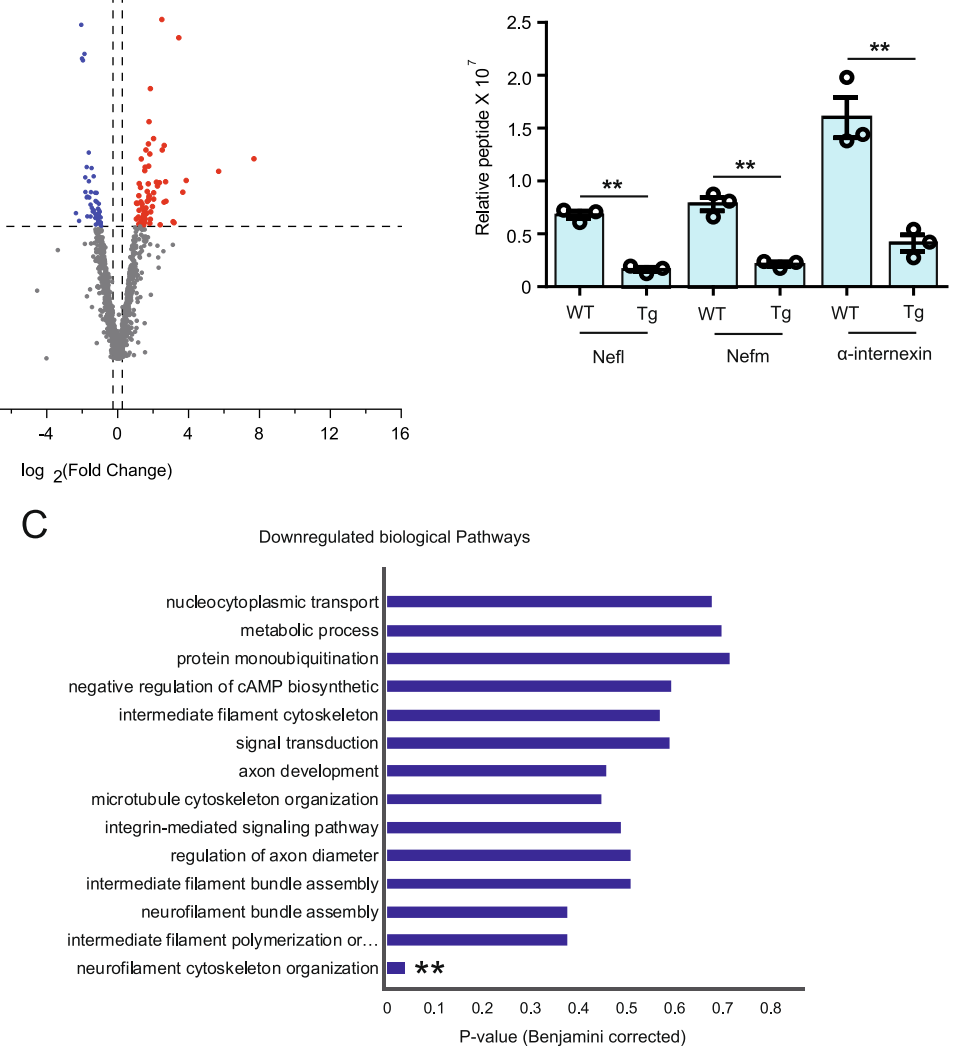

Fig. 7 Translational suppression of neurofilament mRNAs in hTDP-43 ${ }^{A 315 T}$ mice. a Volcano plot of Affymetrix 2.0 ST chip results of mRNA isolated from brain neuronal ribosome complex of NFL-rRFP and NFL-rRFP; $h T D P-43^{A 315 T}$ mice at 12 months of age. Experiments were conducted in three biological replicates ( $n=6$ mice/condition). $\mathbf{b}$ Volcano plot of proteomic results of peptide isolated from brain neuronal ribosomal complex of NFL-rRFP and NFL-rRFP; hTDP-43 ${ }^{A 315 T}$ mice analyzed with the mass spectroscopic methods at 12 months of age. Experiments were conducted in three biological replicates ( $n=6$ mice/condition). c GO functional analysis of isolated peptide from brain neurons of NFL-rRFP;hTDP-43 ${ }^{\text {A315T }}$ mice revealed neuronal cytoskeletal deregulation. Data showing levels of ribosome-bound (d) mRNAs and (e) peptides for cytoskeletal proteins Nefl, Nefm and a-internexin in NFL-rRFP and NFL-rRFP,hTDP-43 ${ }^{\text {A315T }}$ mice at 12 months of age. Data represents mean \pm sem. ${ }^{* *} p<0.01$

cell death at high dose or prolonged treatment [40]. Addition of methoxy group to withaferin A significantly reduced toxic properties $[41,42]$. Here, the IMS-088 compound obtained from IMSTAR therapeutics (Vancouver) is basically the 4-O-methyl withaferin-A which is better tolerated at high doses $(60 \mathrm{mg} / \mathrm{kg})$ than
withaferin-A in mice. A pharmacokinetic study with ${ }^{14} \mathrm{C}$-labeled-IMS-088 revealed that this novel analog penetrates the blood brain barrier after oral intake. The present study shows that oral administration of IMS-088 for 8 weeks in transgenic mouse models with TDP-43 proteinopathy led to reduction of RIPA-buffer insoluble 
A

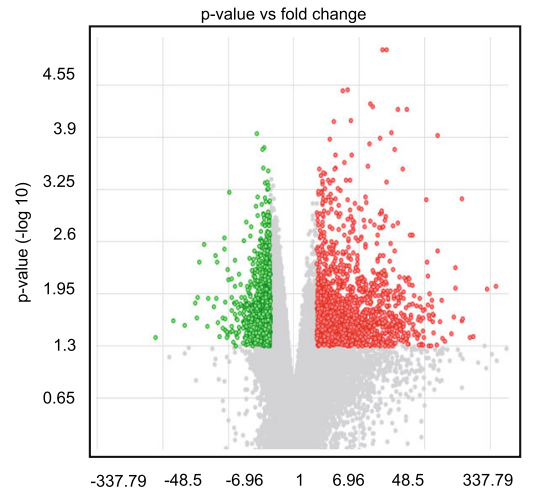

B

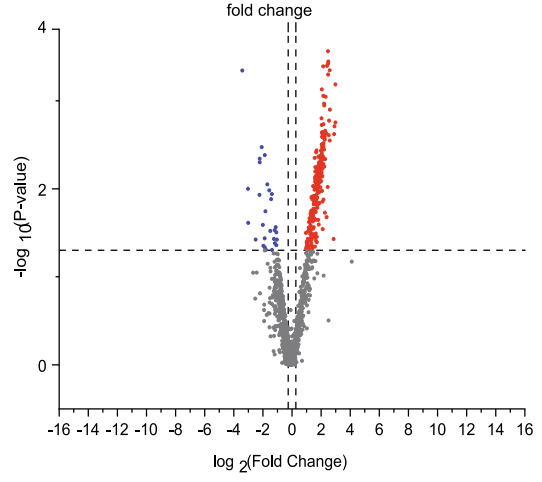

C

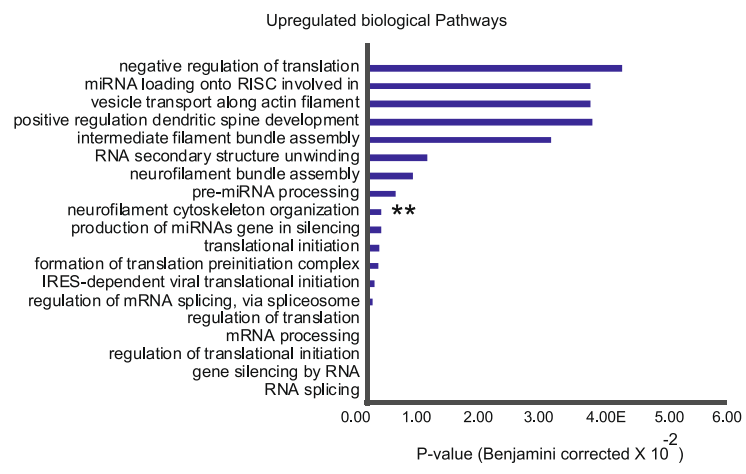

D
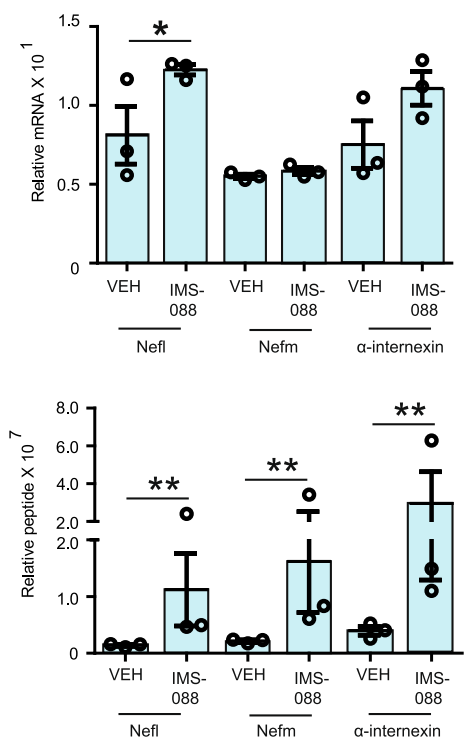

$\mathrm{F}$
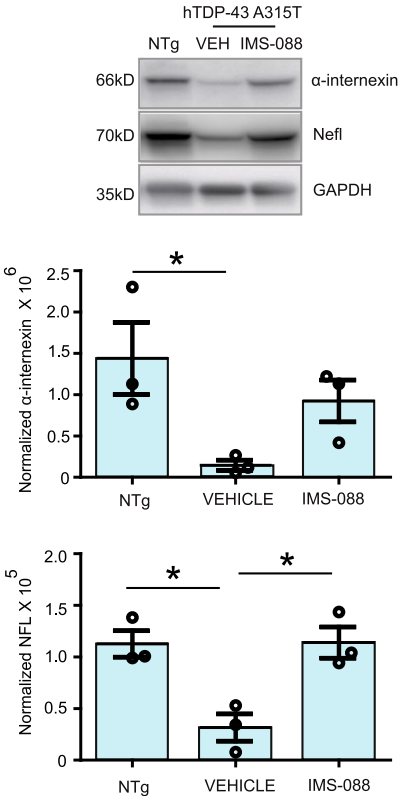

Fig. 8 IMS-088 treatment reversed the neuronal translational defects associated with TDP-43 proteinopathy. a NFL-rRFP;hTDP-43 ${ }^{\text {A315T }}$ mice treated with IMS-088 or vehicle for 8 weeks and the mRNA bound to neuronal ribosome complex were analyzed with the Affymetrix 2.0 ST chip at 12 months of age. $\mathbf{b}$ Volcano plot of proteomic results of peptide isolated from brain neuronal ribosomal complex of NFL-rRFP; $h$ TDP-43 ${ }^{\text {A315T }}$ mice treated with IMS-088 or vehicle were analyzed with the mass spectroscopic methods at 12 months of age. Experiments were conducted in three biological replicates ( $n=6$ mice/condition). c GO functional analysis of isolated peptide from brain neurons of NFL-rRFP;hTDP-43 ${ }^{\text {A315T }}$ mice treated with IMS-088 or vehicle revealed IMS-088 rescued the neuronal cytoskeletal deregulation in mhTDP-43 mice. Levels of (d) mRNA and (e) peptide detected for neuronal cytoskeletal proteins nefl, nefm and a-internexin (Statistical analysis used was $p$-value limma test; Data represents mean \pm sem. $\left.{ }^{*} p<0.01\right)$. f Immunoblot and graph represent levels of a-internexin and NFL in the mouse brain of different groups ( $n=3 ; 1$-way ANOVA; Bonferroni's multiple comparison test, ${ }^{*} p<0.05$ )

TDP-43 levels and of cytoplasmic TDP-43 aggregates in the brain and spinal cord. The IMS-088 treatment increased the levels of Beclin-1 and LC3BII which are autophagic markers. From these results, we conclude that clearance of cytoplasmic TDP-43 by IMS-088 in the mouse models is likely the result of a boost of autophagic activity. In other mouse models of neurodegenerative diseases, autophagy induction was also found to promote the clearance of different aggregated proteins including huntingtin [43], $\alpha$-synuclein [44] and amyloid beta [45]. 
It has been suggested that autophagy insufficiency occurring during aging may contribute to increase of misfolded proteins [46].

Our data suggests that clearance of excess cytoplasmic TDP-43 by IMS-088 administration had beneficial effects in part by reversing the translational defects in neurons. Thus, IMS-088 treatment was found to restore the dysregulated translational profile of brain neurons in one-year old mice expressing hTDP-43 mutant. Of particular interest was the finding that IMS-088 rescued the translational repression of neurofilament proteins in the brain of the mice expressing mutant hTDP-43.

Treatment of mice expressing mutant hTDP- 43 with IMS-088, an inhibitor of NF- $\mathrm{kB}$ activity, led to reduction of microgliosis and astrogliosis (Fig. 4). NF- $\mathrm{KB}$ is a transcription factor playing a key role in inflammatory responses including genes encoding cytokines and chemokines [47]. Microglia-specific inhibition of NF- $\mathrm{kB}$ pathway has also shown to attenuate neuroinflammation and extended survival by several weeks in the SOD1 ${ }^{\text {G93A }}$ mice [17].

\section{Conclusions}

We discovered with the use of transgenic mice expressing hTDP-43 mutants that cytoplasmic accumulation of TDP-43 can alter the translation of specific mRNAs in brain neurons including a suppression of neurofilament protein synthesis. Oral administration of IMS-088 reversed the translational damage in neurons, reduced inflammation and mitigated cognitive deficits. IMS-088 is a NF-kB inhibitor that induced concurrently autophagy, a process which likely contributed to clearance of cytoplasmic TDP-43 aggregates. The results suggest that IMS-088 and perhaps other inducers of autophagy might represent promising therapeutics for TDP-43 proteinopathies.

\section{Supplementary Information}

The online version contains supplementary material available at https://doi. org/10.1186/s13024-020-00420-5.

Additional file 1: Figure S1. IMS-088 reduced levels of phospho-TDP43 in the brain of hTDP-43 ${ }^{\mathrm{A} 315 \mathrm{~T}}$ mice. The anti-phospho-TDP-43 antibody (pSer410, Sigma-Aldrich, USA) was used for immunodetection ( $n=3$ independent experiments).

Additional file 2: Figure S2. Inhibition of autophagy blocks IMS-088mediated reduction of hTDP-43 aggregates. Immunoblots ad quantification of RIPA insoluble (A) and soluble (B) TDP-43 in HEK293 cells treated with ethacrynic acid with or without IMS-088 and Bafilmycin A1. HEK 293 cells were treated for $3 \mathrm{~h}$ with $50 \mu \mathrm{M}$ Ethacrynic acid in serum free media and then with Bafilomycin A1 (300 nM) with or without IMS-088 for $6 \mathrm{~h}$. Post-treatment, levels of RIPA insoluble (A) or soluble (B) hTDP-43 in Hek293 cells were determined by immunoblotting with anti-human TDP43 antibody (Abnova). ( $n=3 ; 1$-way ANOVA with Bonferroni's multiple comparison test as the post-test). Graphs show mean \pm sem.

Additional file 3: Figure S3. (A) Schematic representation of HAmRFP1-tagged murine Rpl10a ribosomal protein construct under control of the NFL 848 promoter to make neuron specific expression (B) Representative sketch showing the process used for generating double transgenic mice (by breeding NFL-RFP1 mice with mhTDP-43 ${ }^{\text {A315T }}$ mice) (C) Representative image showing DAPI (blue), NeuN a neuronal marker and RFP (red) in the brain of hTDP-43 ${ }^{\text {A315T }}$ mice and NfL-RFP,hTDP-43 ${ }^{\text {A315T }}$ double transgenic mice. (D) Representative image of experimental protocol used for the Ribotrap experiment.

Additional file 4: Figure S4. (A) Representative data of upregulated peptide associated GO biological function in NFLrRFP;hTDP-43 ${ }^{\text {A315T }}$ mice in comparison to NFLrRFP mice (B) Representative data of upregulated peptide associated GO biological function in NFLrRFP; hTDP-43 ${ }^{\text {A315T }}$ mice treated with IMS-088 in comparison to saline treatment. (C) Pie chart showing the majority of mRNA dysregulated after IMS-088 treatment found in Affymetrix Mouse Genome 430 analysis were pseudo or nonregulated genes with unknown function (D) Representative data of altered peptide including Pin1 in NFL-RFP; hTDP-43A315T and the impact of IMS-088 treatment on the reversal of neuronal translational profile in NFL-RFP; hTDP-43A315T mice.

\section{Additional file 5.}

\section{Acknowledgments}

We thank Florence Roux-Dalvai, Proteomics Platform; Annick Ouellet, Gene Expression Analysis Platform. We also thank Kallol Dutta, Geneviève Soucy, Christine Bareil, Banshi Nath and Karine Plourde for their technical assistance. We thank IMSTAR Therapeutics (BC, Canada) for generously providing IMS088 for our study. JPJ is a co-founder of IMSTAR therapeutics. JPJ holds a Canada Research Chair Tier 1.

\section{Authors' contributions}

SK designed the study, performed Ribotrap experiment, analyzed the data, performed western blots, immunohistochemistry, cell culture experiment and wrote the manuscript. DP, PC and SK performed the behavioral test, statistical analysis and animal dissection for isolating brain and spinal cord. HB and JK generated the NFL-rRFP transgenic mice. Further, SK did characterisation and validation of the transgenic mice model. JPJ designed the study and wrote the manuscript. The authors read and approved the final manuscript.

\section{Funding}

This work was funded by a grant from the Canadian Institutes of Health Research (CIHR), by a Hudson grant from the ALS Society of Canada and Brain Canada Foundation.

\section{Competing interests}

JPJ holds shares in IMSTAR Therapeutics which provided the IMS-088 compound. All other authors have no competing interests.

Received: 15 May 2020 Accepted: 14 December 2020

Published online: 07 January 2021

\section{References}

1. Buratti E. Advances in genetics, vol. 91: Elsevier; 2015. p. 1-53. https://doi. org/10.1016/bs.adgen.2015.07.001.

2. Liu EY, et al. Loss of Nuclear TDP-43 is Associated with Decondensation of LINE Retrotransposons. Cell Rep. 2019;27:1409-1421. e1406.

3. Pozzi $\mathrm{S}$, et al. Virus-mediated delivery of antibody targeting TAR DNAbinding protein-43 mitigates associated neuropathology. J Clin Invest. 2019; 129:1581-95.

4. Arai T, et al. TDP-43 is a component of ubiquitin-positive tau-negative inclusions in frontotemporal lobar degeneration and amyotrophic lateral sclerosis. Biochem Biophys Res Commun. 2006;351:602-11.

5. Arai T. Significance and limitation of the pathological classification of TDP43 proteinopathy. Neuropathology. 2014;34:578-88.

6. Burrell JR, et al. The frontotemporal dementia-motor neuron disease continuum. Lancet. 2016;388:919-31.

7. Mackenzie IR, Neumann M. Molecular neuropathology of frontotemporal dementia: insights into disease mechanisms from postmortem studies. J Neurochem. 2016;138:54-70, 
8. Freibaum BD, Chitta RK, High AA, Taylor JP. Global analysis of TDP-43 interacting proteins reveals strong association with RNA splicing and translation machinery. J Proteome Res. 2010;9:1104-20.

9. Coyne AN, et al. Futsch/MAP 1B mRNA is a translational target of TDP-43 and is neuroprotective in a Drosophila model of amyotrophic lateral sclerosis. J Neurosci. 2014;34:15962-74.

10. Majumder P, Chu J-F, Chatterjee B, Swamy KB, Shen C-KJ. Co-regulation of mRNA translation by TDP-43 and fragile $X$ syndrome protein FMRP. Acta Neuropathol. 2016;132:721-38.

11. Russo A, et al. Increased cytoplasmic TDP-43 reduces global protein synthesis by interacting with RACK1 on polyribosomes. Hum Mol Genet. 2017;26:1407-18.

12. Swarup V, et al. Pathological hallmarks of amyotrophic lateral sclerosis/ frontotemporal lobar degeneration in transgenic mice produced with TDP43 genomic fragments. Brain. 2011;134:2610-26.

13. Picher-Martel V, Valdmanis PN, Gould PV, Julien J-P, Dupré N. From animal models to human disease: a genetic approach for personalized medicine in ALS. Acta Neuropathol Commun. 2016;4:70.

14. Dutta K, Patel P, Rahimian R, Phaneuf D, Julien J-P. Withania somnifera reverses transactive response DNA binding protein 43 proteinopathy in a mouse model of amyotrophic lateral sclerosis/frontotemporal lobar degeneration. Neurotherapeutics. 2017;14:447-62.

15. Wang I-F, et al. Autophagy activators rescue and alleviate pathogenesis of a mouse model with proteinopathies of the TAR DNA-binding protein 43. Proc Natl Acad Sci. 2012;109:15024-9.

16. Swarup V, et al. Deregulation of TDP-43 in amyotrophic lateral sclerosis triggers nuclear factor KB-mediated pathogenic pathways. J Exp Med. 2011; 208:2429-47.

17. Frakes $A E$, et al. Microglia induce motor neuron death via the classical NFKB pathway in amyotrophic lateral sclerosis. Neuron. 2014;81:1009-23.

18. Banu MR, Ibrahim M, Prabhu K, Rajasankar S. Withaferin-A protects the nigral dopamine neuron and recovers motor activity in aged rats. Cells Tissues Organs. 2020;208:1-7.

19. Hooper C, Jackson SS, Coughlin EE, Coon JJ, Miyamoto S. Covalent modification of the NF-KB essential modulator (NEMO) by a chemical compound can regulate its ubiquitin binding properties in vitro. J Biol Chem. 2014;289:33161-74.

20. Yamada K, Santo-Yamada Y, Wada K. Stress-induced impairment of inhibitory avoidance learning in female neuromedin B receptor-deficient mice. Physiol Behav. 2003;78:303-9.

21. Iguchi Y, et al. Exosome secretion is a key pathway for clearance of pathological TDP-43. Brain. 2016;139:3187-201.

22. Charron G, Guy L-G, Bazinet M, Julien J-P. Multiple neuron-specific enhancers in the gene coding for the human neurofilament light chain. J Biol Chem. 1995;270:30604-10.

23. Doyle JP, et al. Application of a translational profiling approach for the comparative analysis of CNS cell types. Cell. 2008;135:749-62.

24. Boutej $\mathrm{H}$, et al. Diverging mRNA and protein networks in activated microglia reveal SRSF3 suppresses translation of highly upregulated innate immune transcripts. Cell Rep. 2017;21:3220-33.

25. Iguchi $Y$, et al. Oxidative stress induced by glutathione depletion reproduces pathological modifications of TDP-43 linked to TDP-43 proteinopathies. Neurobiol Dis. 2012;45:862-70.

26. Trocoli A, Djavaheri-Mergny M. The complex interplay between autophagy and NF-KB signaling pathways in cancer cells. Am J Cancer Res. 2011;1:629.

27. Mitchell JC, et al. Wild type human TDP-43 potentiates ALS-linked mutant TDP-43 driven progressive motor and cortical neuron degeneration with pathological features of ALS. Acta Neuropathol Commun. 2015;3:36.

28. Nelson PT, et al. Limbic-predominant age-related TDP-43 encephalopathy (LATE): consensus working group report. Brain. 2019;142:1503-27.

29. Côté F, Collard J-F, Julien J-P. Progressive neuronopathy in transgenic mice expressing the human neurofilament heavy gene: a mouse model of amyotrophic lateral sclerosis. Cell. 1993;73:35-46.

30. Lee MK, Marszalek JR, Cleveland DW. A mutant neurofilament subunit causes massive, selective motor neuron death: implications for the pathogenesis of human motor neuron disease. Neuron. 1994;13:975-88.

31. Collard J-F, Côté F, Julien J-P. Defective axonal transport in a transgenic mouse model of amyotrophic lateral sclerosis. Nature. 1995;375:61-4.

32. Julien J-P. Neurofilaments and motor neuron disease. Trends Cell Biol. 1997; $7: 243-9$
33. Beaulieu JM, Nguyen MD, Julien JP. Late onset of motor neurons in mice overexpressing wild-type peripherin. J Cell Biol. 1999;147:531-44.

34. Yuan A, et al. Neurofilament subunits are integral components of synapses and modulate neurotransmission and behavior in vivo. Mol Psychiatry. 2015; 20:986-94.

35. Yuan A, et al. Neurofilament light interaction with GluN1 modulates neurotransmission and schizophrenia-associated behaviors. Transl Psychiatry. 2018:8:1-12.

36. Strong MJ, et al. TDP43 is a human low molecular weight neurofilament (hNFL) mRNA-binding protein. Mol Cell Neurosci. 2007;35:320-7.

37. Ghosh K, et al. Withaferin a induced impaired autophagy and unfolded protein response in human breast cancer cell-lines MCF-7 and MDA-MB231. Toxicol in Vitro. 2017:44:330-8.

38. Patel P, Julien J-P, Kriz J. Early-stage treatment with Withaferin a reduces levels of misfolded superoxide dismutase 1 and extends lifespan in a mouse model of amyotrophic lateral sclerosis. Neurotherapeutics. 2015;12:217-33.

39. Zhang $\mathrm{Q}-\mathrm{Z}$, et al. Protection against cerebral infarction by Withaferin a involves inhibition of neuronal apoptosis, activation of PI3K/Akt signaling pathway, and reduced intimal hyperplasia via inhibition of VSMC migration and matrix metalloproteinases. Adv Med Sci. 2017;62:186-92.

40. Vaishnavi $\mathrm{K}$, et al. Differential activities of the two closely related withanolides, Withaferin A and Withanone: bioinformatics and experimental evidences. PloS one. 2012;7:e44419.

41. Huang C, et al. 3beta-methoxy derivation of Withaferin-a attenuates its anticancer potency: bioinformatics and molecular evidences. Med Aromat Plants. 2015:4:2167-0412.100021.

42. Chaudhary A, et al. 2, 3-Dihydro-33-methoxy Withaferin-a protects normal cells against stress: molecular evidence of its potent cytoprotective activity. J Nat Prod. 2017:80:2756-60

43. Ravikumar B, et al. Inhibition of mTOR induces autophagy and reduces toxicity of polyglutamine expansions in fly and mouse models of Huntington disease. Nat Genet. 2004;36:585.

44. Crews $\mathrm{L}$, et al. Selective molecular alterations in the autophagy pathway in patients with Lewy body disease and in models of a-synucleinopathy. PLoS One. 2010;: $:$ e9313.

45. Spilman $P$, et al. Inhibition of mTOR by rapamycin abolishes cognitive deficits and reduces amyloid- $\beta$ levels in a mouse model of Alzheimer's disease. PLoS One. 2010;5:e9979.

46. Kroemer G. Autophagy: a druggable process that is deregulated in aging and human disease. J Clin Invest. 2015;125:1-4.

47. Liu T, Zhang L, Joo D, Sun S-C. NF-kB signaling in inflammation. Signal Transduct Target Ther. 2017;2:17023.

\section{Publisher's Note}

Springer Nature remains neutral with regard to jurisdictional claims in published maps and institutional affiliations.

\section{Ready to submit your research? Choose BMC and benefit from:}

- fast, convenient online submission

- thorough peer review by experienced researchers in your field

- rapid publication on acceptance

- support for research data, including large and complex data types

- gold Open Access which fosters wider collaboration and increased citations

- maximum visibility for your research: over $100 \mathrm{M}$ website views per year

At $\mathrm{BMC}$, research is always in progress.

Learn more biomedcentral.com/submission 